\title{
Algumas Contingências da Produção Acadêmica Universitária: um Estudo Preliminar
}

Some Contingencies of University Academic Production: a Preliminary Study

Algunas Contingencias de la Producción Académica Universitaria: un Estudio Preliminar

Taisa Scarpin Guazi Universidade Estadual Paulista "Júlio de Mesquita Filho" Carolina Laurenti Universidade Estadual de Maringá

http://dx.doi.org/10.1590/1982-3703002262013 
Resumo: Considerando estudos que investigaram correlações positivas entre alta-produtividade acadêmica e problemas orgânicos e psicológicos, esta pesquisa, orientada pelos pressupostos teóricos da Análise do Comportamento, buscou caracterizar algumas contingências envolvidas na produção acadêmica universitária, priorizando os aspectos psicológicos/comportamentais (sentimentos, emoções, pensamentos) dessas relações. Participaram deste estudo, de cunho exploratório, três professores bolsistas produtividade em pesquisa do CNPq. Os resultados, obtidos por meio de uma entrevista semiestruturada, e discutidos segundo o método de interpretação analítico-comportamental, permitiram identificar contingências distintas que participaram da origem e da manutenção do comportamento de pesquisar. As condições que instalaram o comportamento de estudar eram predominantemente aversivas, marcadas pelo controle por regras e pelo sentimento de responsabilidade. Já o comportamento contemporâneo de pesquisar passou a ser controlado, de modo preponderante, pelas consequências naturais positivas dessa atividade, emergindo, nessas relações, sentimentos de prazer com respeito ao pesquisar. A despeito dessas condições, verificou-se também baixa autoestima e algumas consequências aversivas tardias em diferentes esferas da vida dos entrevistados, decorrentes de uma dedicação exclusiva à academia. Este estudo reitera a necessidade de se delinear caminhos alternativos a uma prática docente permeada por consequências aversivas imediatas ou em longo prazo, construindo condições mais libertárias no exercício da profissão.

Palavras-chave: Ensino superior. Análise do comportamento. Pesquisa científica. Análise de contingências.

Abstract: Taking into consideration studies researching positive correlations between high academic productivity and organic and psychological problems, this research, guided by the Behavior Analysis theoretical background, meant to describe some contingencies concerning academic production, giving priority to the psychological/behavioral aspects (such as feelings, emotions and thoughts) of those relations. There were three participants in this study, of exploratory intent, all three being academic professors with productiveness scholarships granted by the CNPq. The results, obtained throughout a semistructured interview, and debated accordingly to the Behavior Analysis interpretation method, allowed the identification of different contingencies taking part in the origin and maintenance of the "behavior of researching". The conditions which installed the "behavior of studying" were prevalently of aversive nature, marked by rule control and the feeling of responsibility. On the other hand, the contemporary "behavior of researching" went on to be controlled, in a major way, by that activity's natural positive consequences, emerging, from those relations, feelings of delight or pleasure regarding researching. In spite of those conditions, the study also verified a low self-esteem and some delayed aversive consequences in different aspects of the interviewee's life, derived from an exclusive dedication towards the academy. This study reasserts the need to outline alternative ways to a lecturing practice pervaded by immediate or long-term aversive consequences, creating more libertarian conditions in the profession.

Keywords: Graduate school. Behavior analysis. Scientific research. Contingency analysis.

Resumen: Considerando estudios que investigan correlaciones positivas entre alta-productividad académica y problemas orgánicos y psicológicos, esta investigación, orientada por el arsenal teórico del Análisis de la Conducta, buscó caracterizar algunas contingencias involucradas en la producción académica universitaria, priorizando los aspectos psicológicos/comportamentales (sentimientos, emociones, pensamientos) de esas relaciones. Participaron de este estudio, de carácter exploratorio, tres profesores bolsistas de productividad en investigaciones del CNPq. Los resultados, obtenidos por medio de una entrevista semi-estructurada, y discutidos según el método de interpretación analítico-comportamental, permitieron identificar contingencias distintas que participaron del origen y de la manutención de la conducta de investigar. Las condiciones que instalaron la conducta de estudiar eran predominantemente aversivas, marcadas por el control por reglas y por el sentimiento de responsabilidad. Ya la conducta contemporánea de investigar pasó a ser controlada, de modo preponderante, por consecuencias naturales positivas de esa actividad, emergiendo, en esas relaciones, sentimientos de placer con respecto al investigar. A despecho de esas condiciones, se verificó también baja autoestima y algunas consecuencias aversivas tardías 
en diferentes esferas de la vida de los entrevistados, decurrentes de una dedicación exclusiva a la academia. Este estudio reitera la necesidad de que se delineen vías alternativas a una práctica docente permeada por consecuencias aversivas inmediatas o a largo plazo, construyendo condiciones más libertarias en el ejercicio de la profesión.

Palabras-clave: Facultades. Análisis de la conducta. Investigación científica. Análisis de contingencia.

\section{Introdução}

A concorrência e a competitividade são fundamentais na manutenção e expansão do sistema capitalista (Rattner, 2009) e, por essa centralidade, atravessam e estruturam as relações estabelecidas entre as mais diversas instituições que constituem o tecido social. Nessa ótica, a competitividade, que permeia as relações entre nações, empresas, redes de comércio e indústria, parece também se estender para o ambiente acadêmico. $\mathrm{Na}$ academia, isso se expressa, em alguma medida, na busca pela excelência, tanto por parte dos professores quanto dos alunos, os quais alcançam reconhecimento na medida em que se destacam nesse ambiente. Tal competitividade encontra ecos nas exigências estabelecidas pelas agências de fomento à pesquisa, que devem ser cumpridas tanto para o consentimento de bolsas-pesquisa para professores e alunos, quanto para manter ou melhorar os indicadores de qualidade dos currículos desses indivíduos (Bosi, 2011). Com relação aos professores universitários, em específico, essas exigências incluem constante produção científica, publicação dos resultados, formação continuada de recursos humanos, liderança de grupos, participação em bancas e congressos, participação em programas de pós-graduação, supervisão e orientação de alunos, entre outras atribuições (Bosi, 2011; CNPq, 2009; Santana, 2011).

As atuais exigências que circunscrevem a rotina do professor universitário têm sido alvo de discussão em vários estudos (Bianchetti, 2008; Bosi, 2011; Maués, 2008; Meis, Velloso, Lannes, Carmo \& Meis, 2003; Santana, 2011; Sguissardi \& Silva Júnior, 2009; Silva, 2008), os quais apontam, invariavelmente, para problemas orgânicos e psicológicos que estão relacionados com o ritmo de trabalho desses profissionais. Nessa direção, Santana (2011, p. 223) discorre sobre a relação diretamente proporcional "entre as doenças cardiovasculares e o número de orientandos e de produção científica por ano" do pesquisador; Meis et al. (2003) e Silva (2008) destacam que a rotina exaustiva a que os profissionais acadêmicos estão expostos contribui para o desenvolvimento da síndrome de burnout. Sguissardi e Silva Júnior (2009) endossam os estudos anteriores ao alertarem para a crescente incidência de doenças mentais entre professores-pesquisadores, como depressão, estresse e síndrome do pânico, bem como para o consumo frequente de psicotrópicos como antidepressivos, ansiolíticos e antiestressantes por essa população.

Considerando esses dados, destaca-se a necessidade de se desenvolver pesquisas que investiguem mais detalhadamente as condições envolvidas na carreira docente, bem como o impacto delas em diferentes esferas da vida desses profissionais, de modo que caminhos alternativos à situação atual sejam vislumbrados. À luz da teoria analítico-comportamental, uma investigação dessa natureza pressupõe o estudo do comportamento humano, entendido como a relação inextrincável do ser humano com seu mundo natural e social (Lopes, 2010; Skinner, 1969). Tal relação pode ser examinada por uma ferramenta conceitual denominada contingência tríplice (Leão \& Laurenti, 2009), a qual especifica os seguintes aspectos do comportamento que devem ser considerados em sua explicação: "o ambiente no qual ocorre a ação" (S), "a ação propriamente dita" (R) e "a consequência da ação" (C) (Lopes, 2010, p. 98). Com efeito, a compreensão de um dado fenômeno psicológico exige o estudo do comportamento inscrito nessas relações de contingências. Além disso, e destoando de uma leitura mecanicista, a Análise do Comportamento entende que tal compreensão também implica em dirigir-se para a história de constituição desse fenômeno ao longo do tempo (Leão \& Laurenti, 2009; Lopes, 2010; Skinner, 1974). Em outras palavras, a teoria analítico-comportamental oferece uma 
explicação histórica do comportamento: os eventos atuais são entendidos na inter-relação das contingências passadas (história de vida do indivíduo) com as contingências presentes (ambiente atual) (Leão \& Laurenti, 2009).

Pautando-se nesses pressupostos e nas pesquisas contemporâneas sobre as circunstâncias que caracterizam a carreira docente no ensino superior, objetivou-se, com este estudo, caracterizar algumas contingências envolvidas no comportamento de pesquisar de professores universitários, realizando um esboço das possíveis contingências originárias e mantenedoras desse padrão comportamental, atentando principalmente para os aspectos psicológicos/comportamentais (sentimentos, emoções, pensamentos etc.) dessas relações.

\section{Método}

Esta pesquisa, de natureza exploratória, contou com a participação de três professores bolsistas de produtividade em pesquisa de uma universidade do interior paranaense (os quais serão identificados, neste estudo, por P1, P2 e $\mathrm{P} 3)$. Os participantes foram selecionados por meio dos dados oferecidos pelo site do Conselho Nacional de Desenvolvimento Científico e Tecnológico (CNPq) (http://plsql1.cnpq.br/divulg/ RESULTADO_PQ_102003).curso). Buscou-se pelos maiores estratos, percorrendo a relação de pesquisadores em ordem decrescente de classificação. A escolha por esse perfil de participante justificou-se: (i) por esse indivíduo estar comprometido a manter uma excelência continuada de acordo com as exigências do CNPq e (ii) pela existência de estudos que correlacionem alta produtividade com problemas orgânicos e também psicológicos (Santana, 2011; Sguissardi \& Silva Júnior, 2009; Silva, 2008).

A pesquisa foi realizada no local de trabalho dos participantes e valeu-se de uma entrevista semiestruturada como instrumento para a obtenção das informações. As perguntas objetivaram identificar contingências passadas envolvidas na ação de estudar e algumas contingências atuais que circunscrevem a ação de pesquisar desses docentes. Convém ressaltar que mesmo diante de situações demasiado complexas, nas quais não é factível controlar e manipular experimentalmente variáveis responsáveis pela origem e manutenção de um dado padrão comportamental, é possível interpretar essas relações com base nos pressupostos teóricos da Análise do Comportamento, eles mesmos fundamentados em estudos empírico-experimentais (Donahoe, 1993; Skinner, 1974). Depreende-se disso que a interpretação é um método legítimo de produção de conhecimento em Análise do Comportamento, o que, por sua vez, justifica o seu uso, neste trabalho, para a análise dos resultados.

Em linhas gerais, os passos que pautaram a interpretação dos dados levantados nesta pesquisa foram os seguintes: (i) transcrição das entrevistas na íntegra; (ii) identificação de regularidades comportamentais no relato dos entrevistados; (iii) descrição das regularidades comportamentais em termos da noção de tríplice contingência e de outros conceitos da teoria analítico-comportamental; (iv) sistematização dessas descrições em categorias temáticas mais amplas (por exemplo: contingências originárias do comportamento de estudar, contingências mantenedoras do comportamento de pesquisar, efeitos aversivos tardios do comportamento de pesquisar etc.) de modo a dar visibilidade às relações encontradas.

\section{Resultados e discussão}

A discussão dos resultados será dividida em dois momentos. Primeiramente, serão descritas as contingências originárias do comportamento de estudar e, em um segundo momento, discutir-se-ão as contingências mantenedoras do comportamento de pesquisar. A importância de examinar separadamente as contingências originárias das contingências mantenedoras dos diversos padrões comportamentais deriva do fato de que a natureza do comportamento é processual (Lopes, 2010), de modo que, quando as contingências mudam, o comportamento também muda em termos de sua função. Ou seja, nem sempre as contingências que instalaram um comportamento são as mesmas contingências que o mantêm - ainda que haja similaridades na forma (topografia) em que ele se apresenta. Considerando esses aspectos, optou-se por nomear o comportamento alvo de investigação das contingências originárias como comportamento de estudar e o comportamento que será discutido nas contingências mantenedoras 
como comportamento de pesquisar. Outro ponto a ser ressaltado refere-se ao fato de que, embora o estudar faça parte da classe de ações do comportamento de pesquisar, esse último compreende um número significativamente maior de ações, conforme será observado no curso desta discussão.

Contingências originárias: comportamento de estudar e condições aversivas

A condição financeira dos entrevistados, nos anos iniciais de suas vidas, não era favorável, o que parece ter contribuído para que eles fossem expostos precocemente a situações que demandavam extrema responsabilidade e elevado desempenho. P1 e P3, por exemplo, começaram a trabalhar muito cedo (ainda adolescentes) para garantir seu próprio sustento e o da família. Segundo Guilhardi (2002), o sentimento de responsabilidade deriva de contingências coercitivas. Uma pessoa extremamente responsável viveria sob controle de coerção e seria produto de uma história de vida na qual várias condições foram associadas como, por exemplo, a ausência de uma comunidade verbal alternativa que tornasse possível a discriminação dos excessos de coerção e exigências muito elevadas de desempenho. Nesse sentido, é possível que o ambiente no qual os entrevistados viveram os anos iniciais de suas vidas tenha sido permeado por controle aversivo. Essa hipótese também orientará as discussões que seguem.

Ao que parece a relação dos entrevistados com o estudo era, inicialmente, caracterizada por condições aversivas. Foi possível observar certa regularidade nas condições que circunscreveram essa relação: (i) como já referido, os entrevistados são oriundos de famílias cuja situação financeira era precária, (ii) seus pais atribuíam grande importância ao estudo e (iii) acreditavam que pelo estudo os filhos alcançariam um padrão de vida melhor. O trecho ${ }^{1}$ abaixo ilustra a discussão:

... esse incentivo eu sempre tive, assim, né (...) de que era muito importante o estudo, isso sempre foi. Em casa sempre teve muito livro, teve muita (...) leitura, então (...) eu acho que, pra mim, era quase que uma coisa quase natural, assim, eu ir para esse canto... Era uma coisa mais ou menos definida pra gente assim (...) não que eles achavam que a gente ia trabalhar numa Universidade, mas que era uma coisa relacionada ao estudo, né, que seria uma coisa certa, assim, que a gente ia viver por conta do estudo que a gente tinha feito né ... É, pra estudo tinha [incentivo], pra estudo tinha (...). Eu lembro que ir pra rua, pra essas coisas, era um desespero, porque a gente queria, na época, era a calça Lee, a famosa calça, quando começou. E a minha mãe não comprava calça Lee nunca, então todos os meus colegas tinham, aqueles calções largos, [risos] mas (...) mas pro estudo, sempre teve... (P2)

Os pais de $\mathrm{P} 2$ parecem ter delimitado muito claramente o meio pelo qual seus filhos alcançariam um padrão de vida melhor: o estudo. Assim sendo, é possível que tenham modelado, no padrão comportamental dos filhos, ações muito específicas que, no caso, se relacionavam com o comportamento de estudar - os reforçadores disponíveis presumivelmente estavam circunscritos às ações relacionadas à vida acadêmica. As contingências arranjadas pelos pais de $\mathrm{P} 2$ para instalar o comportamento de estudar nos filhos foram a tal ponto efetivas que o entrevistado afirma que "era quase que uma coisa quase natural, assim, eu ir para esse canto", isto é, para a vida acadêmica.

Segundo Skinner (1953), a modelagem é um procedimento por meio do qual um novo comportamento é instalado pelo reforçamento diferencial de aproximações sucessivas de um determinado comportamento. Se, por um lado, havia uma ampla rede de reforçadores para a ação de estudar, por outro, ações que destoavam ou não estavam relacionadas com o estudar eram punidas, extintas ou aconteciam sob contexto extremamente coercitivo; isso pode ser reiterado na seguinte assertiva de $\mathrm{P} 2$ : "Eu lembro que ir pra rua, pra essas coisas, era um desespero".

Com relação a $\mathrm{P} 1$ :

Meu pai comprava muitos livros, comprava muitos livros. Como eles estavam à disposição (...) acho que a família incentivava [estudar] $\mathrm{sim}$, incentivava sim. Até o fato de meus pais serem um pouco severos, né, não deixava você ir no cinema todos os dias (...). Isso de certa forma incentivava a leitura: ia fazer o quê? Lê ainda é barato... Você vai na 
esquina, comprar um lanche, bebe uma coca-cola, você gasta. (P1)

Conforme assinalou $\mathrm{P} 1$, os passeios em prol ao lazer eram raros, mas, em contrapartida, sua família investia muito em livros. Mais uma vez parece que os reforçadores disponíveis estavam relacionados ao estudar e, portanto, as variações comportamentais de P1 reforçadas e mantidas estavam vinculadas à vida acadêmica. Aparentemente, estudar era para P1 um padrão de esquiva: seja para evitar o tédio, seja para evitar a situação aversiva que um passeio com custo financeiro poderia provocar - em suma, estudar tornava o ambiente menos aversivo, sendo uma das poucas ações reforçadas, ainda que negativamente.

No trecho abaixo, P3 ilustra a relação que seus pais tinham com o estudo:

Eles não, vendo na minha família desde, desde pequeno havia, meu pai sempre queria que a gente não passasse pelo sacrifício que ele passou na vida, que tivesse(e) (...), que a gente estudasse realmente, tanto que assim que ele conseguiu, né... Então todos fizeram faculdade... E(ee) então ele conseguiu realmente formar, ele, realmente a ideia dele era, ele não queria se aventurar pra onde (...) pra onde não tinha faculdades, deu a maior força pra que eu fosse pra [cidade do interior paranaense] pra, então eles me apoiaram bastante nisso. (P3)

Os pais de P3 também parecem ter destacado o estudo como o caminho para que os filhos alcançassem um padrão de vida melhor, ou menos sofrido. As condições arranjadas por eles para instalar e manter o comportamento de estudar nos filhos envolvia, inclusive, o fato de não se aventurarem em cidades nas quais não havia universidade. Em outras palavras, os pais de $\mathrm{P} 3$ parecem ter se comportado, ao longo da educação de seus filhos, em função de seguir uma regra cuja consequência era instalar o padrão de estudo no repertório comportamental dos filhos. Possivelmente, os reforçadores disponibilizados pelos pais de P3 estavam restritos a ações que se relacionavam direta ou indiretamente com o estudo, bem como é possível que esse contexto tenha sido permeado por controle aversivo. Em suma, os pais de $\mathrm{P} 3$ apresentavam uma regra muito clara de que era preciso estudar, caso contrário, P3 teria um futuro tão sofrido quanto o do pai. Vale ressaltar que as ações de esquiva acontecem sob controle de experiências passadas e de condições atuais; ou seja, apesar da ação-esquiva evitar uma consequência aversiva ou punitiva que poderia ocorrer, é incorreto dizer que ela está sob controle de condições futuras (Sidman, 1989/2009). Nesse sentido, estudar para evitar "um futuro tal qual o do pai", que inicialmente pode ter funcionado como regra - ações de esquiva também podem ser aprendidas por meio de regras (Sidman, 1989/2009) - e após como autorregra, era uma ação que, por um lado, poderia obter reforçadores sociais pelo fato do indivíduo obedecer às prescrições dos pais e, por outro, poderia ser reforçada, porque tornava o ambiente menos aversivo.

Outro ponto que merece ser esclarecido diz respeito ao conceito de regras. De acordo com Skinner (1969), os diversos comportamentos também podem ser instalados e mantidos por meio de descrições verbais construídas socialmente - processo denominado de comportamento governado por regras. As regras descrevem contingências e funcionam como estímulos discriminativos: especificam a relação entre estímulos antecedentes, ações e consequências (Skinner, 1969) e alteram a probabilidade de ocorrência de uma determinada ação (Nico, 1999). A regra gera dois tipos de consequências: (i) uma especificada pela regra e (ii) outra liberada pela pessoa que verbalizou a regra, contingente ao seguimento dessa (Nico, 1999). No caso de P3, por exemplo, a regra delineava a necessidade de estudar (ação) para evitar um futuro permeado por sofrimento semelhante ao do pai (consequência). Essa regra gerava, por um lado, a consequência direta do estudar (conhecimento, sucesso profissional, condição de vida melhor) e, por outro, a consequência liberada pelo pai (amenização das condições aversivas presentes ou liberação de reforçadores positivos). Dentre as duas consequências elucidadas, é a segunda (de natureza social e cultural) que tem papel fundamental na instalação e manutenção do comportamento de seguir regras (Matos, 2001). Tendo em vista o exposto, é possível que as ações de estudar, trabalhar, garantir o próprio sustento e ajudar no da família, observadas precocemente na história de vida dos entrevistados, tenham sido instaladas pela combinação de regras 
e reforçamento negativo. É possível dizer ainda que os reforçadores disponíveis para os entrevistados estavam circunscritos às ações relacionadas com o estudo e, talvez, com ações controladas (governadas) pelas regras emitidas pelos seus pais.

Contingências atuais/mantenedoras do pesquisar

Se o padrão comportamental de estudar dos entrevistados foi presumivelmente instalado por meio da inter-relação entre reforçamento negativo e regras, a manutenção desse padrão parece derivar de reforçadores naturais, inerentes à atividade de pesquisa. Convém discutir um pouco sobre o que sejam os reforçadores naturais. Skinner (1968) discorre sobre dois tipos de reforçadores: (i) os reforçadores naturais e (ii) os reforçadores arbitrários. Os reforçadores naturais derivam diretamente das ações, já os reforçadores arbitrários são produtos indiretos delas. Por exemplo, produzir conhecimento científico (consequência), com a pesquisa (ação) configura um reforçador natural da ação de pesquisar, ao passo que receber um prêmio, condecorações, ou recompensa financeira pelo conhecimento produzido ilustram reforçadores arbitrários.

Com relação ao padrão comportamental de estudar convém esclarecer alguns pontos. Skinner (1968) destaca que as consequências finais da ação de estudar são adquiridas em longo prazo, não sendo elas, portanto, as responsáveis por instalar ou manter, inicialmente, essa ação. Nesse sentido, Skinner (1968) enfatiza a importância de estabelecer reforçadores arbitrários para esse padrão comportamental, até que, finalmente, os reforçadores naturais comecem a surgir e os primeiros percam a função. Matos (2001), por seu turno, pontua que as regras são utilizadas em situações nas quais as contingências naturais são fracas, têm magnitude pequena ou, então, operam em longo prazo, como é o caso da ação de estudar. Segundo a autora, geralmente esse comportamento é instalado e mantido por meio de regras até que as contingências, que envolvam reforçadores naturais em longo prazo, comecem a operar.

Tendo no horizonte essa discussão, os excertos abaixo são ilustrativos:
Comecei a gostar de estudar no colegial. Não estudava muito (...) antes disso não. No colegial, metade do colegial, eu comecei a estudar mais intensamente... Depois que eu adquiri vontade de estudar eu estudava mesmo, estudava bastante. (P1) Mas não sou, não tiro férias longas (...)... Não consigo ficar muito tempo parado. Se bem que hoje você pode levar seu notebook e trabalhar nas férias, né?... Mas depois de uma semana sem fazer nada, eu começo a ficar nervoso. (P1) Isso é voluntário [trabalhar]. Eu posso muito bem chegar amanhã e dizer "olha não faço mais nenhuma pesquisa e pronto, tá acabado"... Então na verdade é (eee) (...) eu fazer ou não fazer (...) é muito mais uma questão de amor próprio - próprio. Aqui(i) (...) infelizmente é isso. (P1)

No primeiro trecho P1 destaca que começou a gostar de estudar no colegial e que, antes disso, ele não estudava muito. Em seguida, o entrevistado afirma que, quando "adquiriu vontade de estudar", passou a fazê-lo de forma mais sistemática. Para a Análise do Comportamento, a experiência de vontade pode ser entendida como a resposta de sentir estados corporais que acompanham uma alta probabilidade de uma ação ocorrer em situações nas quais sua ocorrência é impedida (Skinner, 1974). A vontade de agir refere-se a comportamentos já instalados e está relacionada com reforçadores positivos (Skinner, 1974). No caso de P1, a experiência de vontade de estudar/pesquisar possivelmente acontecia em situações nas quais tal operante era impedido de ocorrer, seja no contexto de férias, licença ou, então, aposentadoria. Ademais, "adquirir vontade", nessa situação, pode sinalizar que os reforçadores naturais da ação de estudar passaram, a partir desse momento, a manter essa classe de ações, ao passo que os reforçadores arbitrários, presentes em contingências de reforçamento negativo e em regras, responsáveis por instalar esse padrão, foram, aos poucos, perdendo sua função.

As afirmações de P1 no que tange à sua inabilidade em "ficar parado", em tirar férias longas e ao "nervosismo" que aparece depois de uma semana de folga, sugerem que ele, frente a situações que sinalizam uma indisponibilidade dos reforçadores naturais do pesquisar, emite ações de esquiva. E, quando isso não soluciona o caráter aversivo 
do contexto (quando é inevitável tirar férias, por exemplo), respostas emocionais, como "nervosismo", são identificadas, o que sugere a presença de controle aversivo. Nesse caso, parece plausível levantar a hipótese de que contextos que não oferecem ocasião para a emissão de ações relacionadas à pesquisa ganharam status de estímulo aversivo condicionado. Ou seja, tirar férias, licença ou iniciar o processo de aposentadoria são ações punidas negativamente, pela retirada dos reforçadores naturais da ação de pesquisar. Segundo Skinner (1953), a punição diminui a frequência de ações semelhantes à punida ocorrerem no futuro. P1, por exemplo, tira férias curtas e não muito frequentes, o que corrobora com a hipótese de que as férias funcionam como estímulo aversivo, sendo, portanto, evitadas. Convém ressaltar ainda que P1 parece exercer contracontrole frente ao contexto punitivo das férias: "Se bem que hoje você pode levar seu notebook e trabalhar nas férias, né?" (P1).

O último excerto merece comentários adicionais. P1 afirma que suas atividades acadêmicas de pesquisador são voluntárias - ele destaca que não há nenhum controle institucional (aversivo ou reforçador positivo) que mantenha essa classe de ações, e finaliza dizendo que faz o que faz "por amor próprio". Disso depreende-se, mais uma vez, que, possivelmente, são os reforçadores naturais, inerentes à atividade de pesquisar, que mantêm esse padrão comportamental do entrevistado. $\mathrm{E}$, conforme destaca Skinner (1953, 1968), quando os reforçadores naturais passam a manter os diversos padrões comportamentais, tendemos a recorrer a explicações mentalistas, porque os reforçadores naturais são mais difíceis de ser identificados do que os reforçadores arbitrários - o excerto, referente a P1, "eu fazer ou não fazer (...) é muito mais uma questão de amor próprio" ilustra bem esse ponto. Ademais, dizer que se manter pesquisando é "por amor próprio" pode indicar que, talvez, a única (ou a mais poderosa) fonte de reforçadores seja, para ele, a academia.

Ainda sobre esse mesmo ponto, com relação a P3:

Sim, sempre gostei [de estudar]. Sempre tive(e) pra(aa), desde, aliás isso desde(ee) o colégio. Mais desde o colégio, o fundamental nem era muito ligado na vida, mas, depois do colégio até agora eu gosto tanto de, tá sempre lendo, sempre aprendendo, né, sempre, a gente nunca acaba de se formar, né? Então, sempre tô, até hoje eu gostou muito disso, gosto muito de tá atualizando, lendo. (P3) Mas na realidade a gente não sente muita(a), vamos dizer, necessidades de férias pra atividade acadêmica, pra atividade de pesquisa, né? Você não tem muito eh(hh) [pausa] sempre me falaram, eu nunca consegui entender muito bem, né, "você trabalha, trabalha, não descansa. Você, (...) fica (...) sofrendo a vida inteira?". Pra mim não é sofrimento, nunca foi. (P3)

Em semelhança com o observado em P1, P3 passou a gostar de estudar no colégio, o que sugere que foi nesse momento que os reforçadores naturais do estudar passaram a controlar esse padrão comportamental, ao passo que o controle aversivo, responsável por instalá-lo, foi perdendo sua função. P3 elucida o quanto gosta de estudar atualmente, o que mais uma vez faz referência aos reforçadores naturais da ação de pesquisar e à sua efetividade em manter esse operante. Outrossim, quando P3 destaca que as ações relacionadas com a pesquisa não são permeadas por sofrimento, ele sugere que a atividade de pesquisar não é realizada sob condições aversivas, bem como sinaliza a presença de reforçadores positivos, representados pelos reforçadores naturais produzidos por esse padrão comportamental. P3 destaca ainda que não sente necessidade de tirar férias. Conforme já pontuado, a experiência de sentir vontade, desejo ou necessidade se refere a padrões comportamentais já instalados e a reforçadores positivos (Skinner, 1974). A assertiva de $\mathrm{P} 3$ pode indicar a presença de condições aversivas no tirar férias, bem como indica que tirar férias não participa do repertório comportamental do entrevistado. Como em P1, as férias sinalizam uma indisponibilidade dos reforçadores naturais vinculados à pesquisa, o que justifica, por seu turno, o padrão de fuga/esquiva apresentado por P3 frente ao contexto de férias.

No que se refere a P2:

As minhas férias convencionais, de "não, agora eu vou sair de férias" são curtas e são muito infrequentes e eu me preocupo um pouco com isso. Eu, por exemplo, eu acho 
que eu tirei, foi em 2006, foi a última vez que eu falei assim "não, hoje eu vou sair de férias". Então saí, e fiquei lá, sei lá, uma semana, dez dias de férias e voltei, saí de férias e voltei... Aí realmente depois de uma semana [parado, de férias] eu tava assim, desesperado, mas eu tinha que aguentar (...). A gente acaba viciando um pouco no trabalho. Como ele é muito prazeroso, eu acabo com muita vontade de voltar pro trabalho ... O trabalho pra mim é um hobby. (P2) Outra coisa característica do pesquisador que eu acho é que você não (...) você não para de trabalhar quando você se aposenta. Então acho que (...) eu teria meu tempo de aposentadoria assim em 2014, quando aposentar, assim, com todos os direitos, todas as condições. Mas certamente, com certeza, eu vou me aposentar, é claro, mas não vou parar de trabalhar como pesquisador, né?! (P2)

Assim como no caso de P1 e P3, o atual padrão comportamental de pesquisar parece ser mantido pelas consequências naturais desse operante. Mais uma vez é possível falar que situações que não apresentam ocasião para a emissão de ações de pesquisar criam contexto para a emissão de respostas de fuga/esquiva, bem como a eliciação de respostas emocionais (sensação de desespero, por exemplo). P2, frente à iminência da aposentadoria, afirma que o pesquisador exerce suas funções em um continuum - ele não encerra suas atividades ao se aposentar. A máxima de P2 está em afirmar que seu trabalho é um hobby e que "vicia" - isso pode sugerir que, talvez, a sua única (ou a mais significativa) fonte de reforçadores sejam as consequências envolvidas no pesquisar.

Skinner (1974) afirma que os sentimentos são produtos que emergem nas relações de contingências, e que "algumas vezes é possível descobrir o que reforça uma pessoa simplesmente perguntando-lhe do que é que ela gosta ou como se sente acerca das coisas" (p. 48). De modo geral, é possível afirmar que os entrevistados trabalham com prazer e gostam do que fazem como pesquisadores, a exemplo de P2 que destaca que a atividade de pesquisar é "muito prazerosa" e "viciante". Esses dados parecem indicar que a atividade de pesquisar é mantida, preponderantemente, por meio de reforçadores positivos (possivelmente os reforçadores naturais da ação de pesquisar).
Outro indicativo dessa hipótese é que, como discutido alhures, contextos ou situações que sinalizam a não ocasião para a emissão de ações de pesquisa são evitadas, além de eliciar respostas emocionais com conotações aversivas, tais como "nervosismo", "desespero" entre outras.

O padrão comportamental de pesquisar dos entrevistados, embora envolva ações responsáveis, não parece estar associado ao sentimento de responsabilidade. Guilhardi (2002) pontua que é possível instalar repertórios comportamentais responsáveis sem que eles estejam vinculados ao sentimento de responsabilidade, bem como é possível que comportamentos responsáveis, instalados por contingências coercitivas, passem a ser mantidos e desenvolvidos por meio de contingências de reforçamento positivo. Dessa forma, os sentimentos associados a esses padrões comportamentais serão outros: liberdade, bem-estar, satisfação - a pessoa trabalha com prazer e não com responsabilidade (que tem função aversiva).

Se nas contingências originárias os padrões comportamentais responsáveis (trabalhar, ajudar no sustento financeiro da família e estudar, por exemplo) presumivelmente foram instalados por meio de contingências coercitivas, e estavam associados ao sentimento de responsabilidade, as contingências que mantêm hoje padrões que se expressam de modo semelhante (a atividade acadêmica, por exemplo) são de reforçamento positivo. Como mencionado alhures, os entrevistados trabalham com prazer, sob controle dos reforçadores naturais da ação de pesquisar - como também é possível observar em:

Sentar pra escrever um artigo, por exemplo, pra mim, é uma (...) é uma febre, assim, é uma coisa que, quando eu engatinho, começo a caminhar, é uma coisa que eu não consigo parar. Pra parar, sabe, me incomoda parar, eu tenho vontade de ficar continuando, continuando sábado, domingo. É gostoso, então, é um esforço assim (...) que eu acho que na verdade é um prazer [risos]. (P2)

Convém ressaltar possíveis exceções da afirmação anterior: as atividades relacionadas com os aspectos burocráticos da pesquisa e com questões administrativas (departamentais 
e coordenação de grupos de pesquisa, por exemplo) parecem continuar a ser mantidas por meio de contingências aversivas - os entrevistados se sentem responsáveis por tais atividades. Este excerto é ilustrativo: “... pra mim isso é um sacrifício, é administração (...). Administração de grupo, administração (...) qualquer que seja, pra mim eu acho que isso (...) isso não me dá prazer (...) mas tem que fazer" (P3).

Os entrevistados são pesquisadores cuja importância científica é reconhecida nacional e internacionalmente. No entanto, eles apresentam dificuldade em exercer autorreconhecimento, que, por sua vez, está estreitamente relacionado com a autoestima. Segundo Guilhardi (2002), o desenvolvimento da autoestima envolve contingências de reforçamento positivo sociais, ou seja, depende, por exemplo, do reconhecimento que os pais expressam aos seus filhos frente às ações deles, com destaque para a pessoa e não para o comportamento. Com boa autoestima, o indivíduo é capaz de exercer autorreconhecimento.

O excerto abaixo exemplifica a já pontuada dificuldade dos entrevistados em exercer autorreconhecimento:

\section{Mas eu não tenho tantas realizações assim, né? Nunca vou ganhar o prêmio Nobel, por exemplo (...). As minhas realizações são bem mais modestas, né... Si(ii)m, meu currículo Lattes é bonito... [voz baixa]. É bonito, eu sei, eu sei, sei. Tenho frustrações também. [pausa]. Deixemos isso pra lá [pausa]. (P1)}

Esses dados encorajam a hipótese de que, talvez, os entrevistados apresentem um padrão comportamental de baixa autoestima. Nessa perspectiva, é possível que o contexto no qual os entrevistados estão inseridos privilegie o reconhecimento das ações, das produções e palestras dos entrevistados e não, propriamente, os entrevistados - isso explicaria a manutenção da baixa autoestima e da inabilidade de autorreconhecimento (Guilhardi, 2002). Por exemplo, os entrevistados são parabenizados pelos artigos publicados, pelas palestras proferidas, mas não são elogiados como pessoas inteligentes ou sábias.

Embora a ação de pesquisar, propriamente dita, seja mantida por meio de reforçadores naturais, e os entrevistados trabalhem não com sentimento de responsabilidade, mas com prazer, uma história de vida na qual se primou pelo reconhecimento das ações, ao invés do reconhecimento das pessoas, inviabiliza ou dificulta que os entrevistados discriminem que são suas ações que produziram e produzem cada uma de suas conquistas.

Similaridades e diferenças entre as contingências originárias e mantenedoras

Conforme já anunciado, a função de um padrão comportamental pode mudar ao longo do tempo ainda que sejam mantidas semelhanças na apresentação desse comportamento (topografia), o que marca a importância de se estudar separadamente as contingências originárias e mantenedoras dos diversos padrões comportamentais. A análise dos dados das entrevistas veio corroborar com esse ponto: o padrão comportamental de estudar, por exemplo, que foi instalado por meio de reforçamento negativo associado com regras (controle aversivo), atualmente é mantido por meio dos reforçadores positivos naturais da ação de pesquisar, ou seja, por meio de reforçamento positivo. Se os comportamentos responsáveis observados nos entrevistados (estudar, por exemplo), no início de suas vidas, foram instalados por meio de controle aversivo, contemporaneamente, os entrevistados trabalham com prazer, ou seja, não se observa o sentimento de responsabilidade, mas os comportamentos responsáveis propriamente ditos.

Vale lembrar ainda que nas contingências originárias, os reforçadores disponíveis estavam circunscritos à ação de estudar, e nas contingências atuais, a fonte mais significativa de reforçadores, para os entrevistados, parece ser a academia. Em outras palavras, uma história de vida na qual as ações relacionadas ao estudo foram, de modo preponderante, reforçadas criou condições para que, atualmente, a academia fosse o contexto mais significativo para obtenção de consequências reforçadoras positivas (com a peculiaridade de que as condições atuais não são, predominantemente, aversivas, como anteriormente eram), de modo que eventuais fontes alternativas de reforçadores parecem não ter valor competitivo com ela. 
Efeitos tardios das contingências do comportamento de pesquisar

Os entrevistados têm, em média, 35 anos de carreira acadêmica, permeada por poucas férias. Essa constatação, somada à hipótese de que, presumivelmente, a mais significativa fonte de reforçadores seja a academia encaminha uma discussão sobre os possíveis efeitos aversivos tardios de algumas contingências de reforçamento positivo contemporâneas. Para Skinner (1971), o indivíduo é livre quando suas ações participam de relações comportamentais que não são permeadas por controle aversivo nem em curto nem em longo prazo. Com base nisso, ele adverte que há um tipo especial de relações comportamentais em que o reforçamento positivo imediato adia as consequências aversivas. Esse tipo de relação, pontua Skinner, é ainda mais escravizadora que as contingências coercitivas imediatas, pois, de um lado, a contingência de reforçamento positivo imediato pode gerar sentimentos de prazer ou de liberdade dificultando a identificação de possíveis contingências aversivas tardias; por outro lado, como as consequências aversivas são atrasadas, elas não ocorrem no tempo necessário para gerar contracontrole, seja na forma de fuga ou de revolta. Com efeito, "liberdade é uma questão de contingências de reforçamento, e não de sentimentos que as contingências geram. A distinção é particularmente importante quando as contingências não geram fuga ou contra-ataque" (Skinner, 1971, p. 37-38).

Aplicando essa discussão ao contexto do pesquisar, é preciso criar condições para que as consequências aversivas postergadas, que estejam envolvidas, sejam adiantadas, trazendo-as para o presente e viabilizando o contracontrole e a construção de relações mais libertárias com a atividade acadêmica. No que se refere aos entrevistados, as contingências de reforçamento, das quais participam os reforçadores positivos naturais da ação de pesquisar, não criam condições para que sejam percebidas as consequências aversivas em longo prazo que podem derivar de um ritmo e de uma vida dedicada somente à academia. Em outras palavras, o fato de os entrevistados apresentarem dificuldades de sair de férias ou de se envolverem em atividades de lazer sugerem que eles não estavam conscientes das consequências aversivas postergadas das contingências das quais participam, e nas quais passaram e passam grande parte de suas vidas.

Não obstante, algumas consequências aversivas já se fazem notar em diferentes esferas da vida dos entrevistados. Eles narraram problemas familiares, de relacionamento interpessoal e de saúde, como estresse, doenças cardiovasculares e problemas respiratórios - aspectos que coadunam com os dados apresentados pela literatura consultada (Meis et al., 2003; Santana, 2011; Sguissardi \& Silva Júnior, 2009). No que concerne às relações estabelecidas no contexto familiar, quando questionados, os participantes delinearam respostas longas, entrecortadas por pausas, destacando o quão conflituosa é essa relação:

Você pode se desenvolve muito, e deixa a família ou pode envolve só com a família e não fazer nada, né, na vida acadêmica. $\mathrm{O}$ ideal seria um meio termo. Eu confesso que, no meu caso(o), eu investi mais na [gagueja levemente] ca, carre, carreira acadêmica, hoje eu vejo isso, né... Então (...) gastei muito, partilhei meu tempo... com o grupo de pesquisa, com as minhas atividades de pesquisa e minhas aulas e pouco pra, pra [voz baixa] vida familiar. Hoje eu vejo que (...) não foi uma decisão das melhores. (P3) É (...) eu acho que (...) [pausa] é difícil (...). Em alguns pontos, é um pouco conflitante, às vezes. Como eu falei, como é um trabalho muito cativante, você acaba se fechando, é muito fácil. Pra mim, era muito fácil, se eu me descuidasse, eu me fechava mesmo, sabe? Me fechava e eu podia tá (...) é (...) um monte de gente conversando e eu tava escrevendo o artigo. Se não fosse com a mão, era com a cabeça e não tava (...) então isso aí eu tive que tomar muito cuidado, né. (P2) Coitada da família, né. [pausa]. A família sempre apanha um pouco. Porque o pesquisador ambicioso, ele se dedica, se dedica menos à família. [pausa]. Eu fiz isso, e conheço muita gente que fez. Porque a pesquisa absorve muito, a pessoa (...). O sujeito está em casa, as crianças brincando ao redor, ele supostamente deveria estar participando da brincadeira e rindo, né, mas a tendência dele é ficar aéreo, pensando nas coisas dele, no laboratório. (P1)

Nos trechos, parece ficar explícito que a relação entre atividade acadêmica e família é conflituosa - aparentemente essa relação não acontece sem que uma das partes seja 
negligenciada. Sidman (1989/2009) destaca que, em um contexto permeado por reforçamento negativo e punição, os indivíduos tendem a elaborar várias rotas de fuga. As pessoas podem "se desligar", por exemplo, daquilo que as desagrada (Sidman, 1989/2009). Aparentemente, quando os entrevistados estão participando de reuniões ou encontros familiares, eles desligam-se, não ficam sob controle das conversas estabelecidas ao seu entorno. Possivelmente, o convívio familiar também sinalize a indisponibilidade de reforçadores naturais da ação de pesquisar, o que faria alusão ao caráter aversivo de "um domingo em família". Mas, por outro lado, a família poderia perceber que o pai, esposo, tio ou avô está distante, desligado do que está acontecendo à sua volta. Isso poderia gerar outras consequências aversivas para o entrevistado - pressão familiar e relatos verbais de cobrança como, por exemplo, "Você nunca está em casa e, quando está, não liga para mim ou para nossos filhos!"; "Pai, você não gosta da gente - você só trabalha". O que, por seu turno, aumentaria a probabilidade de os entrevistados emitirem outras respostas de fuga e esquiva.

Ademais, os participantes da pesquisa parecem agir, no contexto familiar, sob controle de regras. $\mathrm{P} 2$, ao destacar que era preciso tomar muito cuidado para não se desligar das interações familiares, sugere a elaboração de autorregras ("quando estou com a família, não posso me desligar deles"), que, em última instância, visariam mantê-lo sob controle dos estímulos presentes (e circunscritos ao) no convívio familiar. Essa discussão encoraja outra hipótese: é possível que reforçadores arbitrários e não naturais (talvez estabelecidos pela própria família) controlem as ações emitidas pelos entrevistados nesse contexto - já que eles parecem não estar sob controle exclusivo das contingências ali existentes (o que, em alguma medida, inviabiliza que os reforçadores naturais surjam e comecem a controlar a ação em pauta).

Outra questão a ser ressaltada refere-se ao fato de a atividade acadêmica ser, quase sempre, solitária. Ainda que os entrevistados tenham uma equipe de trabalho, a produção de artigos, correções de trabalhos e afins são, praticamente, executados solitariamente. A assertiva de P1, que segue, sugere ainda que a presença de outras pessoas pode, inclusive, atrapalhar o andamento dessas atividades: "As melhores frases eu escrevi em casa, que não tinha ninguém pra me atrapalhar" (P1). Uma história de vida na qual os reforçadores estavam circunscritos a aspectos relacionados ao estudo e, portanto, as variações comportamentais estavam, primordialmente, restritas a essa esfera, não oferece (ao menos de forma satisfatória) condições propícias para o desenvolvimento de habilidades sociais. Segundo Del Prette e Del Prette (2006), as habilidades sociais referem-se a várias classes de comportamento social que são emitidas no âmbito das relações interpessoais, conforme a demanda. Os autores pontuam ainda que, caso as habilidades sociais não sejam aprendidas no decorrer da vida do indivíduo, é possível, por meio de treinamentos, ensiná-las - principalmente por meio de estratégias grupais. Desse ponto, deriva-se a importância da convivência em grupo para o desenvolvimento dessas habilidades.

Diante do exposto, parece plausível supor que os entrevistados apresentam, em alguma medida, dificuldades em lidar com o outro, principalmente se esse outro participar de interações sociais extra-acadêmicas. Lazer, férias, convívio familiar seriam contextos para que as habilidades sociais fossem modeladas nos entrevistados, no entanto, eles parecem apresentar um forte operante de fuga e esquiva dessas situações.

Em suma, as relações comportamentais caracterizadas por reforçamento positivo imediato condicionadas a consequências aversivas tardias podem produzir profundo sofrimento. Em outras palavras, as contingências do comportamento de pesquisar, a despeito do reforçamento positivo envolvido, podem ser mais subjugadoras que libertárias. Os entrevistados dedicaram suas vidas à produção de conhecimento científico, contribuíram grandemente para o desenvolvimento da universidade, no entanto, estiveram sob controle, preponderante, dos reforçadores naturais da ação de pesquisar. E, só agora, quando já viveram a maior parte de suas vidas, as consequências aversivas começam a surgir: os entrevistados começam a delinear (ainda com pouca nitidez) as consequências que um repertório comportamental restrito 
à academia traz para suas vidas, para vida de seus familiares e amigos.

\section{Considerações finais}

Convém ressaltar as limitações metodológicas que permearam este estudo. O número reduzido de participantes, por exemplo, não consegue oferecer um panorama geral ou de importância estatística das relações comportamentais envolvidas na produção acadêmica do professor pesquisador brasileiro, bem como o cunho exploratório desta pesquisa, a utilização de entrevistas e da interpretação também trazem outras restrições quanto ao escopo e à extensão das discussões empreendidas. A despeito dessas considerações, esta pesquisa abre o flanco para que novos estudos sobre essa temática, calcados em metodologias distintas, sejam realizados. Além disso, esta pesquisa chamou a atenção para um aspecto psicológico/ comportamental que não foi contemplado, de modo sistemático, na literatura consultada: o fato de a atividade de pesquisar ser regida por contingências de reforçamento, das quais participam reforçadores positivos naturais e o sentimento de prazer relacionado ao comportamento de pesquisar. Os reforçadores naturais, como destaca Skinner (1968), são inexauríveis e mantêm alta a probabilidade de emissão de um padrão comportamental - esses aspectos, associado à falta de fontes de reforçadores alternativas, lançam luz à importância que a atividade de pesquisar tem na vida de P1, P2 e P3. Não obstante ter destacado contingências de reforçamento positivo do comportamento de pesquisar, este estudo não obscurece os problemas destacados pela literatura, como os problemas orgânicos e psicológicos enfrentados pelos professores universitários, também verificados nos entrevistados deste estudo. O conjunto desses dados demonstra a complexidade do fenômeno sob investigação, e reitera a necessidade de que mais estudos, que versem sobre essa problemática, sejam feitos, a fim de que possam contribuir para que os professores construam caminhos e condições mais libertárias no exercício da sua profissão. 


\section{Taisa Scarpin Guazi}

Graduada em Psicologia pela Universidade Estadual de Maringá, Maringá. Mestranda no Programa de Pós-Graduação em Psicologia do Desenvolvimento e Aprendizagem da Universidade Estadual Paulista "Júlio de Mesquita Filho", Bauru, SP. Brasil.

E-mail: taisa_guazi@hotmail.com

\section{Carolina Laurenti}

Mestre e Doutora em Filosofia pela Universidade Federal de São Carlos. Professora Adjunta do Departamento de Psicologia da Universidade Estadual de Maringá, Maringá - PR. Brasil. E-mail: laurenticarol@gmail.com

Endereço para envio de correspondência:

Universidade Estadual de Maringá, Departamento de Psicologia, Secretaria do Departamento de Psicologia, Bloco 118, sala 4. Avenida Colombo, 5790. Jardim Universitário. CEP 87020-900 - Maringá, PR - Brasil.

Recebido 28/12/2013, Aprovado 04/09/2014. 
Bianchetti, L. (2008). Pós-graduação em educação: processo e resultados de uma "indução voluntária". Universidade e Sociedade, 17(41), 143-161.

Bosi, A. P. (2011). Feios, sujos e malvados: intensificação do trabalho docente e produtividade acadêmica. Educação e Sociedade, 20(47), 133-148.

Conselho Nacional de Desenvolvimento Científico e Tecnológico - CNPq. (2009). Bolsas individuais no país - Anexo I da RN-016/2006. Nova Redação dada pela RN 009/2009, publicada no DOU em 30/04/2009. Recuperado em 03 de novembro de 2013, do CNPq < http:// www.cnpq.br/view/-/journal_content/56 INSTANCE_OoED/10157/100343

Del Prette, A., \& Del Prette, Z. A. P. (2006). Habilidade sociais: conceitos e campo teóricoprático. Recuperado em 8 de agosto de 2013, de http://www.rihs.ufscar.br.

Donahoe, J. W. (1993). The unconventional wisdom of B. F. Skinner: The analysis-interpretation distinction. Journal of the Experimental Analysis of Behavior, 60(2), 453-456. http://dx.doi. org/10.1901/jeab.1993.60-453. PMid:16812708

Guilhardi, H. J. (2002). Auto-estima, autoconfiança e responsabilidade. In M. Z. S. Brandão, F. C. S. Conte, \& S. A. B. Mezzaroba (Orgs.), Comportamento humano: tudo (ou quase tudo) que você precisa saber para viver melhor (pp. 63-98). Santo André: ESETec Editores Associados.

Leão, M. F. F. C., \& Laurenti, C. (2009). Uma análise do modelo de explicação no behaviorismo radical: o estatuto do comportamento e a relação de dependência entre eventos. Interação em Psicologia, 13(1), 165-174.

Lopes, C. E. (2010). O behaviorismo radical. In A. A. L. Ferreira (Org.), A pluralidade do campo psicológico (pp. 91-108). Rio de Janeiro: UFRJ.

Matos, M. A. (2001). Comportamento governado por regras. Revista Brasileira de Terapia Comportamental e Cognitiva, 3(2), 51-66.

Maués, O. (2008). O produtivismo acadêmico e o trabalho docente. Universidade e Sociedade, 17(41), 21-31.
Meis, L., Velloso, A., Lannes, D., Carmo, M. S., \& Meis, C. (2003). The growing competition in Brazilian science: rites of passage, stress and burnout. Brazilian Journal of Medical and Biological Research, 36(9), 1135-1141. http://dx.doi. org/10.1590/S0100-879X2003000900001. PMid:12937778

Nico, Y. (1999). Regras e insensibilidade: conceitos básicos, algumas considerações teóricas e empíricas. In R. R. Kerbauy \& R. C. Wielenska (Orgs.), Sobre comportamento e cognição psicologia comportamental e cognição: da reflexão teórica à diversidade da aplicação (Vol. 4, pp. 31-39). Santo André: ARBytes.

Rattner, H. (2009). Os limites da competitividade. Revista Espaço Acadêmico, 9(99), 47-50.

Santana, O. C. (2011). Docentes de pós-graduação: grupo de risco de doenças cardiovasculares. Acta Scientiarum Education, 33(2), 219-226.

Sguissardi, V., \& Silva Júnior, J. R. (2009). Trabalho intensificado nas federais: pós-graduação e produtivismo acadêmico. São Paulo: Xãma.

Sidman, M. (2009). Coerção e suas implicações (M. A. Andery \& T. M. Sério, trads.). Campinas: Livro Pleno. (Trabalho original publicado em 1989).

Silva, G. A. G. C. (2008). Sob aparente desistência, trabalhadores do ensino sofrem, doentes, com a síndrome de Burnout. Universidade e Sociedade, 17(41), 133-142.

Skinner, B. F. (1953). Science and human behavior. New York: Macmillan Company.

Skinner, B. F. (1968). The technology of teaching. New York: Appleton-Century-Crofts.

Skinner, B. F. (1969). Contingencies of reinforcement: a theoretical analysis. New York: AppletonCentury-Crofts.

Skinner, B. F. (1971). Beyond freedom and dignity. New York: Alfred A. Knopf.

Skinner, B. F. (1974). About behaviorism. New York: Alfred A. Knopf. 